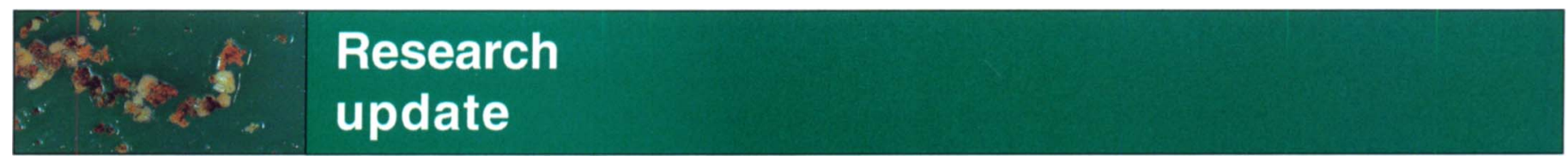

\title{
Scientists score dustbusting efforts in Antelope Valley
}

Tn the semiarid Antelope Valley of Southern California, falling water tables and increasing pumping costs have led many growers to fallow or abandon thousands of acres of once productive farmland.

That can spell trouble in this section of northern Los Angeles County, where spring wind gusts of 30 to 35 miles an hour are not uncommon. The bare soil of abandoned farmland, overgrazed ranchland, and areas disturbed by recreational activities can blow into huge columns of dust, causing blinding dust storms and traffic accidents. The blowing dust can also have adverse respiratory effects and cause severe property damage.

"The record rains of the 1997-98 winter have temporarily alleviated dust problems in the Antelope Valley, but El Niño is a short-term weather aberration," said Dave Vaughn, UC Riverside staff research associate. "Periods of drought will inevitably return, and we have to develop methods for long-term dust control."

In this issue, Vaughn and colleagues evaluate the success of methods used by the Dustbusters

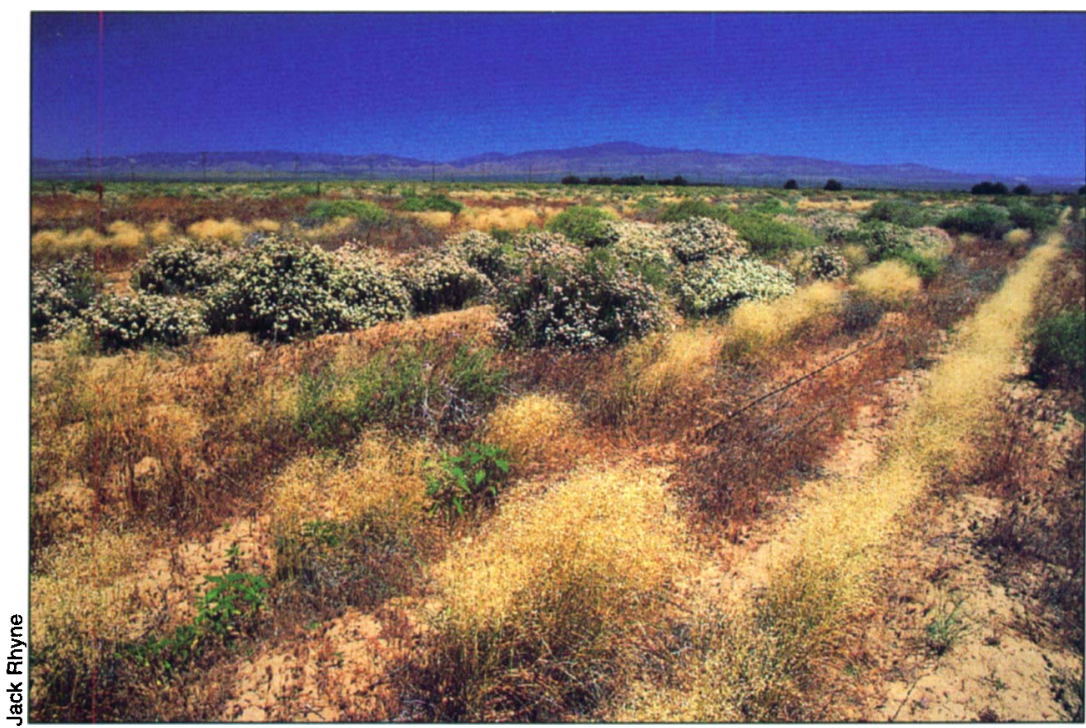

Perennial Indian ricegrass outperformed shrubs in sandy areas of the revegetated acreage in the Antelope Valley.
Task Force, a coalition of federal, state, local and private organizations formed in 1991 to mitigate dust problems in the Antelope Valley (see pages 8 to 18). That year, after 5 years of drought and decades of sheep grazing and farm abandonment, helicopter surveys revealed 11,000 acres of severely eroding Valley soil. Residents had complained about blowing dust and sand during periods of high winds, and on Feb. 17, a dust storm was blamed for 16 car accidents occurring within a 45-minute period.

In the spring of 1992, the Dustbusters successfully initiated revegetation of a 2,500-acre area and also made effective use of wind barriers. Their revegetation attempts were aided by uncharacteristically high rainfall of 10 inches between January and March of 1992.

In parallel field trials begun in 1994, Vaughn and co-researchers found that establishing perennial shrub cover, while the most desirable long-term solution, is unreliable and difficult.

"Natural desert vegetation does not readily recolonize these lands, and many annual "weedy" plants, particularly the non-native Russian thistle or tumbleweed, infest abandoned fields; such annuals do not adequately stabilize the soil against wind erosion," said Vaughn.

The scientists also found that soil disturbance (such as tilling) can delay native shrub establishment. High soil nitrogen levels left over from previous farming were found to favor invasive, undesirable annuals. Low-nutrient soils - those more like natural desert soil - resisted non-natives and were hospitable to colonization by native shrubs.

Based on field trials, the researchers recommend fourwing saltbush as the best species for revegetation in the Antelope Valley. Physical barriers such as wind fences were also useful as short-term controls.

"These findings are important not only for the Antelope Valley, but to other semiarid agricultural areas where farmland may be fallowed or abandoned in the future," Vaughn said.

Agricultural dust created by cultivation and harvesting practices is a continuing concern 


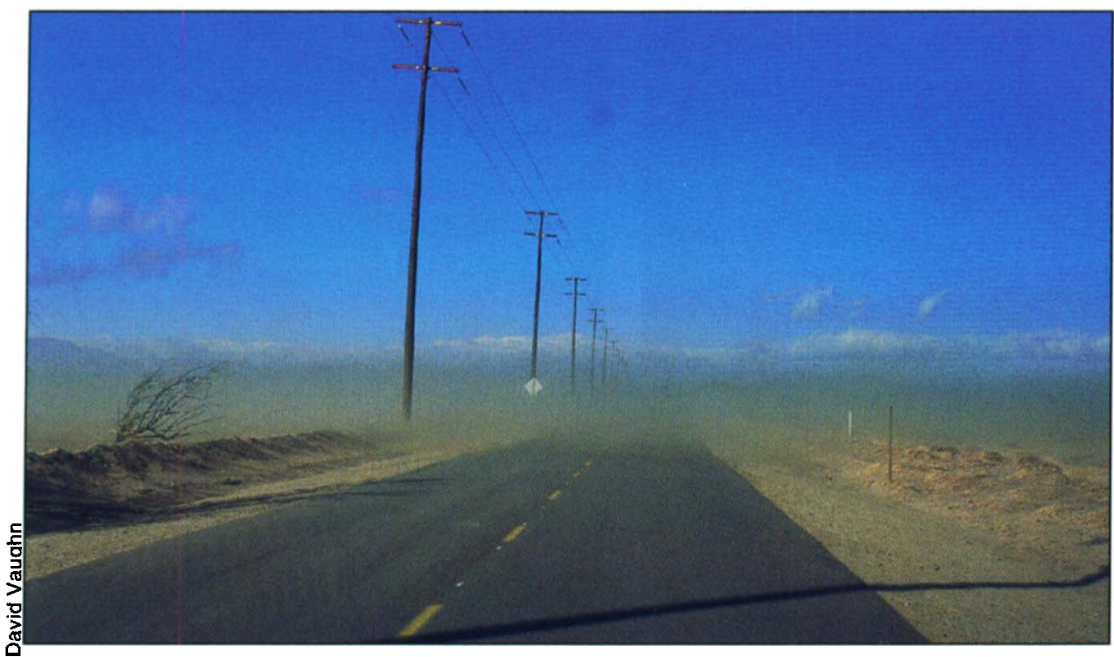

Abandoned farm land can contribute blowing dust, which can obscure visibility.

throughout the Central Valley, where it contributes to dust storms and air pollution by particulate matter 10 microns or less in diameter (PM-10).

In addition, previous studies have shown that Environmental Protection Agency standards for PM-10 are frequently exceeded in the San Joaquin Valley. Soil dust from a variety of sources comprises about $60 \%$ of the PM-10 in the Valley annually.

Because PM-10 particles are small enough to penetrate the lungs, they can threaten people's health. Studies have shown that in general the coarse particles in PM-10 dust come from agricultural fields, deserts and roads, while finer particles come from motor vehicle exhaust as well as industrial and residential combustion. But scientists still know few specifics about where airborne particles come from, where they go, what is in them and how the various components affect people's health. UC researchers are working to answer these questions and to find ways for farmers to reduce $\mathrm{PM}-10$ production.

The first step in determining how the particulate matter standards will affect farmers is finding out how much agriculture contributes to PM-10. UC Davis ecologist Lowell Ashbaugh is working towards that in a 5-year, USDAsupported study of particulate matter in the San Joaquin Valley.

\section{-Editor}

\section{Summer boating main source of lake's MTBE}

Usicas sing a Sierra Nevada lake as a laboratory, UC Davis scientists have found that summertime recreational boating is the primary source of MTBE in the lake's water, and that the contamination most likely stems from unburned fuel in engine exhaust, not spills.

The study at Donner Lake is part of an overall effort to learn more about the sources, fate and transport of the gasoline oxygenate additive in California's water.

Researchers, including John Reuter and Brant Allen of UC Davis' Tahoe Research Group, found that $86 \%$ of the variation in the seasonal trend of total lake MTBE levels was explained by recreational boating. Neither urban runoff nor precipitation contributed significantly, the researchers concluded, based on low concentrations of MTBE in the lake during spring months.

MTBE (methyl tert-butyl ether) is classified by the U.S. Environmental Protection Agency as a possible human carcinogen. The Donner Lake findings are among the first to show conclusively the impact of motorized boating on MTBE surface-water concentrations. The results have been reviewed by the U.S. Geological Survey and are being used in scientific discussions of MTBE nationwide.

$$
- \text { Editor }
$$

Buckwheat contributed significant vegetative cover in the 2,500 acre area. 